\title{
Narrativas e identidades docentes: cultura visual e prática pedagógica
}

\begin{abstract}
RESUMO: Este trabalho toma como objeto de investigação as narrativas orais de professores para, a partir delas, entender as trajetórias pessoais e profissionais de inserção na docência. Tem como objetivo problematizar a trajetória e formação docente a partir de narrativas e como este mesmo percurso se posiciona no trato com as imagens enquanto prática pedagógica inserida no contexto contemporâneo da cultura visual. Enfatiza, a partir daí, as percepções e utilização dos artefatos visuais nas salas de aula como possibilidade de produção de conhecimento conectado ao mundo contemporâneo, por meio das visualidades. Para desenvolvimento do trabalho foram realizadas entrevistas narrativas com dois professores da Educação Básica, das quais se depreendem as razões por que optaram pelo magistério e os modos de utilização das imagens nas salas de aula. A investigação nos mostrou que embora essas questões apresentem avanços, ainda conservam visões restritas à ideia das visualidades como ilustração dos conteúdos ou elementos dispensáveis/ inadequados a depender da área de conhecimento.
\end{abstract}

Palavras-chave: Trajetórias de formação. Cultura visual. Prática pedagógica.

\section{Narrativas orais e autobiografia: contextualizando a proposta do estudo}

Pensar a formação docente através das histórias de vida dos professores é uma prática que vem sendo utilizada por pesquisadores na área da Educação. Esses relatos vêm se configurando matéria-prima para estas investigações que revelam trajetórias individuais e coletivas, carregadas de contextos e relações inseridas na diversidade e na construção da identidade desses profissionais.

A presente investigação surge das discussões sobre as "narrativas orais" enquanto dispositivo e campo de pesquisa, inseridas no contexto da identidade, formação e prática docente, na disciplina "Docência e Diversidade" do Programa de Pós-Graduação em Educação e Diversidade (MPED), da Universidade do Estado da Bahia (Uneb), buscando compreender esse movimento em diálogo com os projetos de pesquisa da turma 2017.2. Neste caso, fizemos conexão com a linha de pesquisa: Cultura Visual, Educação e Linguagem, com o objetivo de compreender a prática docente de professores da educação básica a partir do uso das imagens. Desse modo, queremos saber o que esses profissionais entendem por Cultura Visual e como essas visualidades se configuram nas práticas pedagógicas, considerando o processo formativo e a construção da sua identida-
Laíla Sampaio Lima Universidade do Estado da Bahia laila.sampaio86@gmail.com Antenor Rita Gomes Universidade do Estado da Bahia antenorritagomes@gmail.com Emanuela Oliveira Carvalho Dourado

Universidade do Estado da Bahia douradoemanuela@gmail.com 
de docente, assim como o vetor formacional que a imagem pode reverberar nas ações de ensino e aprendizagem.

Este estudo de abordagem qualitativa busca compreender percepções, contextos e as relações múltiplas desse processo de formação e prática docente. No que diz respeito à metodologia, escolhemos trabalhar com a produção e análise das "narrativas orais", utilizando a técnica das entrevistas narrativas do método (auto)biográfico, por entender que se trata de um recurso investigativo privilegiado por imbricar realidades diversas geo-histórico e socialmente contextualizadas. Ela nos ajudará a compreender os percursos dos educadores na escolha pela docência, suas "dores e as delícias" da/na profissão, relacionados ao uso de imagens na trajetória formativa. A intenção foi que essas narrativas pedagógicas respondessem alguns dos nossos questionamentos acerca das suas memórias da entrada na profissão e do uso das imagens nas suas trajetórias como profissionais docentes.

Compreendemos que as narrativas orais podem ser um campo fértil para as ciências sociais e humanas, pois produzem informação num nível de realidade aproximada, que compreende uma orientação teórico-metodológica sob a qual vem se desenvolvendo um método de investigação onde as histórias de vida, biografias, autobiografias e narrativas individuais e coletivas vêm sendo utilizadas na pesquisa em educação enquanto processo de produção de conhecimento. (PINEAU, 2006; REIS, 2008; SOUZA, 2006a, 2006 b etc.)

Enquanto método de pesquisa, a (auto)biografia potencializa o singular direcionado ao universal. Desse modo, narrativas de vivências, experiências retomadas pela memória, fatos repletos de informações muitas vezes de cunho pessoal e afetivo têm sido utilizados para responder questões de investigações em diversas áreas. Nesse sentido, esse recurso metodológico de narrar e produzir conhecimentos a partir delas exige uma postura ética, na qual o pesquisador necessita de "Um rigor outro" (GALEFFI; MACEDO; PIMENTEL, 2009), ao olhar para interpretar e compreender aquilo que foi exposto nas verbalizações memorialísticas dos entrevistados.

Partindo da perspectiva que as narrativas orais são campo de coleta de informações, elas evidenciam elementos que, ativados no contexto da memória dos professores entrevistados, reverberam realidades, ideologias e discursos. Sobre isso, Souza (2011, p. 13) nos diz que, 
[...] Trajetórias de vida e fragmentos biográficos articulamse através de ações coletivas, aprendizagem informal e experiências sociais como constitutivas das culturas, identidades, subjetividades e diversidades dos sujeitos em seus territórios de vida-formação

Nesse contexto, podemos inferir que, em consonância com a opção teórico-filosófica e metodológica, o estudo revela as relações intersubjetivas dos sujeitos, considerando a forma como se percebe no mundo e como se manifesta no tempo e espaço. Portanto, esta investigação se insere, também, num espaço de múltiplas possibilidades, leituras, intelecções e se ocupa dos processos, das construções sociais, de identidade e realidades. Na investigação em questão, isso se deu via narrativas memorialísticas da trajetória formativa e profissional de docentes da Educação Básica. Portanto, nega um fim acabado às respostas para as mais complexas ou simples questões, pois, enxerga os objetos em constante relação com o mundo, em um movimento contínuo de diálogos e possibilidades. (MACEDO, 2000) Assim, as opções metodológicas se posicionam multirreferencialmente, a fim de, a partir das narrativas docentes, adentrar em compreensões a respeito das relações entre a Cultura Visual nas experiências e práticas de professores.

\section{Narrativas, formação e identidade docente}

A riqueza das narrativas orais revela um sujeito em conexão com um passado pessoal potencializado no presente. (REIS, et al., 2014) Nesse sentido, inspirados em Galeffi, Macedo e Pimentel (2009, p. 15), lembramos o "[...] esforço do pensamento humano em conectar-se com a totalidade do vivido e do vivente, tendo-se em vista a autocondução responsável e consequente da vida de relação presente." Esse percurso que o entrevistado faz através das suas memórias vão evidenciar elementos tanto objetivos como subjetivos, que, poderão nos apresentar questões para além da troca de informações ou de conteúdos. No caso desta investigação, servirão para interpretar e compreender elementos a respeito da formação e a da construção da identidade de professores e suas relações com a Cultura Visual e práticas pedagógicas. As experiências reveladas transbordam em aspectos fundamentais para o entendimento desse processo, caracterizando-se em um momento de compreensão tanto dos entrevistados individualmente, como 
do contexto em que está inserido. (REIS; MUYLAERT; SARUBBI; GALLO; NETO, 2014)

Nesse entendimento, este estudo realizou entrevistas narrativas com dois professores da Educação Básica da região de Jacobina, município do interior da Bahia. Para tanto, foram escolhidos professores com formação em áreas distintas de conhecimento: um licenciado em Geografia pela Uneb e outro bacharel em Física pela Universidade Estadual de Feira de Santana (UEFS). O objetivo de ouvir professores com formação em áreas distintas foi perceber se, e como isso pode se diferenciar ou se aproximar no que diz respeito à problematização da escolha da docência, sua formação, e a experiência com o uso das imagens na prática pedagógica que desenvolve.

Desse modo, foi realizado um encontro individual com os professores que, em aproximadamente 30 minutos, narraram suas experiências a partir de uma proposta contextualizada com base nos objetivos deste artigo. Por meio de perguntas, buscamos encontrar nas narrativas as respostas para alguns questionamentos acerca de suas trajetórias formativas: por qual razão optou pela área da educação e da docência? Como isso aconteceu? O que você entende por "Cultura Visual"? Com qual frequência as imagens aparecem como recurso? Em quais situações? Quais principais dificuldades no uso das imagens na sua prática docente? Dessa forma, propomos a seguinte orientação para a entrevista: "Narre sua prática pedagógica com a Cultura Visual, desde a escolha pela docência, enfatizando sua opção pela profissão, o uso de imagens na sua área de atuação como recurso didático, suas impressões acerca do ensino e aprendizagem, apresentando as principais dificuldades no uso dessas imagens na escola."

Esse start possibilitou aos docentes ativarem suas memórias e narrarem suas experiências. Elas foram gravadas e transcritas. Todas as respostas foram contempladas nas memórias formativas narradas. A entrevistadora em momento algum interferiu, inferiu ou interrompeu esse processo, com o objetivo de possibilitar maior liberdade aos docentes entrevistados e maior qualidade na construção de informações que devem emergir do contexto pessoal, identitário e emocional de cada um. A seguir, veremos como essas transcrições retomam e respondem a essas perguntas, levando a possíveis interpretações e compreensões acerca da formação docente dos entrevistados, conforme intenções da pesquisa. Contudo, 
algumas categorias teóricas (de análise) que, de forma imanente orientaram a proposta narrativa, também aparecem nas questões as quais, os participantes das pesquisas, explícita e/ou implicitamente, as trouxeram nas suas narrativas. Portanto, elas também se configuram como subcategorias que emergiram do campo. Desse modo, consideramos em cada subtítulo subsequente a categoria teórica e a categoria de campo como subcategoria subjacente a cada uma: PROFISSÃO DOCENTE: escolha e profissionalização; CULTURA VISUAL: formação docente e práticas pedagógicas; EDUCAÇÃO E VISUALIDADES: práticas pedagógicas e possibilidades.

Seguindo a orientação dos procedimentos éticos para a pesquisa com seres humanos, procuraremos manter o sigilo da identidade dos participantes da pesquisa. Nesse intento, chamaremos aqui o Professor de Geografia de Professor A e o de Física de Professor B.

\title{
Profissão docente: escolha e profissionalização
}

A escolha de uma profissão, seja ela em qualquer área, já se caracteriza como um momento de valor significativo e de relativa importância para qualquer pessoa. Escolher a carreira com a qual iremos conviver revela um sentido de identidade que é construída pela nossa trajetória de vida e formação. Desse modo,

\begin{abstract}
Muitos fatores influenciam na escolha de uma profissão, de características individuais a convicções políticas e religiosas, valores e crenças, situação político-econômica do país, a família e os pares. A literatura aponta a família como um dos principais fatores que ajudam ou dificultam no momento da escolha e na decisão do jovem como um dos fatores de transformação da própria família. (SANTOS, 2005, p. 58)
\end{abstract}

A escolha da profissão docente também atravessa esses aspectos: um caminho traçado por nós, levando-nos à condição atual dessa profissão. Por outro lado, o contexto de desvalorização e baixa remuneração revelam um cenário de esvaziamento dos cursos de licenciatura em todo país. Para Soares (2002), a escolha profissional nos constitui, nos posicionando enquanto sujeitos aptos para produção de recursos necessários à nossa sobrevivência e de nossos dependentes. Assim, acerca da escolha pela docência como profissão, o Professor A verbalizou: 
Não tive escolha... ou era estudar alguma coisa ou era continuar na minha cidade como cobrador... só tinha a Uneb em Jacobina e lá tinha os cursos... (pausa) só de professor... achei que geografia parecia comigo porque viajava muito na Águia Branca olhando as paisagens e tal... aí veio vestibular e consegui entrar... não tinha o que fazer... poderia ser outra coisa.... olha foi um tiro no escuro... fui embora para Jacobina e nunca mais voltei...quer dizer, voltei para ver os parentes...só. (PROFESSOR A, ENTREVISTA NARRATIVA, 2017)

O outro professor também revelou que a docência não foi uma escolha:
Ah!... longa história viu?! Meus pais quiseram me mandar para Feira ${ }^{1}$ pra estudar e eu fiz o vestibular pra engenharia e não passei... aí olhei lá que Física era pouco concorrido e fiz... passei!! (Risos).... aí fui pra lá...eu não queria ser professor, mãe é professora, sei como é...foi um caminho que não escolhi...sou bacharel...não tenho licenciatura mas eu tinha que trabalhar, já era pai tinha um bebê.....sustentar o menino, fui pra sala de aula.(PROFESSOR B, ENTREVISTA NARRATIVA, 2017).

A docência nos dois casos não foi uma opção voluntária ou realização pessoal. A carreira no magistério surge na vida desses professores como uma alternativa possivelmente rápida e emergencial. As narrativas indicam que os participantes da entrevista escolheram a docência por razões distantes do desejo de tornar-se professor. Chama atenção esse fato, uma vez que a carreira docente na atualidade sofre com questões referentes à profissionalização, onde os entrevistados atravessam as adversidades da profissão, o que implica na baixa autoestima. Além disso, nos dois contextos, podemos inferir um menor comprometimento qualitativo, pois, são professores que não revelam à docência como escolha de vida e estão inseridos numa realidade de não valorização da prática docente. Em uma pesquisa com alunos do curso de licenciatura em Biologia de uma universidade pública, Frasson e Campos (2008, p. 1572), também revelou que os

Licenciandos que não tinham pretensão de dar aulas e apenas fizeram licenciatura ou por falta de opção, no caso do curso noturno, ou para complementar a formação, como foi visto no integral, continuam não querendo ser professores ao término do curso por motivos apresentados por eles, como: desvalorização 
da profissão, baixos salários, responsabilidade muito grande e desestímulo gerado pelo sistema educacional atual, pelas escolas e alunos.

Logo, conhecer as razões pelas quais a carreira da docência foi escolhida, as implicações disso para os envolvidos e a função social da escola, nos possibilita repensar a formação docente e suas propostas, em que se compreenda a realidade profissional através de experiências concretas, para assim "reconhecer e assumir, com clareza, a complexidade e as condições reais e objetivas da profissão" (FRASSON;CAMPOS, 2008, p. 1572) Neste sentido, a construção da identidade docente é um importante aspecto da formação de professores, devendo ser condição imprescindível para a escolha da profissão. Nesse veio, Nóvoa (2010) enfatiza a construção da identidade diretamente relacionada com a profissionalização. O autor argumenta que há uma necessidade de negarmos a visão romântica da profissão e reconhecermos que a "tecnicidade e cientificidade" docente não encerra a sua formação. Entende, assim, que é fundamental o olhar para o "pessoa-professor e professor- pessoa" no sentido de propor e desenvolver com os docentes práticas de autoformação que possibilitem (re)elaborações de narrativas pessoais e profissionais. (NÓVOA, 2010) Segundo o autor, esse caminho vem de uma necessidade de autoconhecimento dentro das perspectivas profissionais. É uma leitura pessoal, individual e subjetiva que se insere no ato desse reconhecer profissional docente. Questões que estão para além de conhecimentos técnicos e científicos aprendidos na academia. Esse exercício do self na vida pessoal relacionada à profissão permitirá reflexividade fundamental para que se adquira uma maior compreensão do seu trabalho e da sua identidade docente. (NÓVOA, 2010)

\section{Cultura visual: formação docente e práticas pedagógicas}

Nas últimas décadas, muito se tem estudado acerca da formação dos professores, especialmente, com as mudanças no cenário global que têm implicado em alterações de todos os setores e relações sociais, dentre elas a escola e a forma de lidar com as informações e a produção do conhecimento. Contemporaneamente, vivenciamos rápidas transformações comunicacionais, como resultado das tecnologias digitais. Desse modo, são frequentes as necessidades de mudanças no meio educativo que trazem para a sala de aula 
discussões que envolvem o valor do texto escrito e texto imagético; bem como a inserção dos recursos midiáticos e tecnológicos, levantando questionamentos sobre a real função pedagógica dessas imagens para o meio escolar. A imagem sempre foi um artefato social utilizado por educadores nas suas práticas educativas. Não raro, ouvimos relatos de docentes e discentes que estiveram envolvidos e expostos a imagens como fonte de conhecimentos disciplinares através de fotografias, do cinema, pinturas, dentre outros. No entanto, essa realidade tem sido "contaminada" por uma chamada "Cultura Visual". Autores como Mitchell (1995) e Barnard (2001) tecem suas considerações para o termo. O primeiro, defende ser um movimento que considera as visualidades e suas representações dentro de uma relação dialógica com outros sentidos e linguagens, ou seja, ela não se fecha em si, existe uma relação de dependência com estruturas extra imagens. O segundo autor enfatiza a Cultura Visual como uma tentativa em "normatizar e prescrever objetos de estudo como sendo a arte, o design, expressões faciais, a moda, tatuagem". (BARNARD, 2001, p. 197, grifo nosso)

É da necessidade de estudar o mundo contemporâneo a partir das visualidades que surge a Cultura Visual. Ela abre caminhos para o consumo do visual como forma de buscar a informação, o significado e o prazer pelos dispositivos visuais e tecnológicos. A imagem agora é a representação desse mundo moderno que é difundido nos meios de comunicação de massa. E a "reprodutibilidade técnica" (BENJAMIN, 1987) dessas imagens configura uma característica importante no conceito de Cultura Visual. Aliás, talvez seja o ponto mais importante para conceituarmos essa nova ideia: para serem consideradas imagens ancoradas na perspectiva da Cultura Visual, esses artefatos necessariamente devem estar superexpostos nos meios.

No entanto, nas narrações oportunizadas por esta pesquisa, os professores não demonstraram familiaridade com o termo Cultura Visual. Ambos dizem não ter segurança do que seria essa cultura, mas revelam fazer uso de imagens na sua prática docente. Vejamos:

Já ouvi falar, por sua causa... penso que deve ser trabalhar com imagens...qualquer uma.... desenho, mapas....eu uso muito imagem em sala de aula, geografia sem imagem não dá...é muito difícil, olha, quando comecei mesmo, falar de espaço urbano e rural para meninos de terceira série....era só no livro didático... hoje temos datashow para projetar imagem, a internet é massa pra isso, 
vai no Google e coloca lá o que tu quiser e clica imagens, aparece tudo. (pausa). Tem o livro didático também, tem muita figura, ilustração, isso já ajuda...na faculdade era ruim, quer dizer, tinha um professor que usava muito a imagem...imagem assim, a gente ia lá no laboratório de cartografia e via as rochas... é imagem, não é? É ver. Já outros professores eram muito texto e teoria. Quer dizer, a maioria usava teoria, teoria, texto, texto. Hoje não faço isso. Texto por texto não atrai os meninos... fica chato e eles não aprendem... a imagem em geografia seduz e se for geografia humana então, nossa! (PROFESSOR A, ENTREVISTA NARRATIVA, 2017)

Olha deve ser algo tipo trabalhar com artes. Eu já ouvi alguém falar alguma coisa, não me lembro onde foi. Mas em Física a gente usa imagem... muito pouco, principalmente quando tratamos de força. Para os alunos não faz sentido aquela seta na cabeça dizendo que é gravidade, ai quando a gente coloca a foto, fica melhor. É aquilo do 'entendeu ou quer que desenhe?'(risos). Usamos muito o número. Número é tudo em Física, mas número é também imagem, representa alguma coisa. Eu acho que número é imagem também... (pausa) só não sei se é cultura visual... É? (PROFESSOR B, ENTREVISTA NARRATIVA, 2017)

Consideramos a ideia de Cultura Visual abordada por Nicholas Mirzoeff (2003). Esse autor trabalha a visualidade como característica do mundo contemporâneo, onde estas se mostram como mecanismo para compreender a vida moderna. Ele nos diz que a Cultura Visual se interessa pelos acontecimentos visuais em que o sujeito busque a informação e o prazer através dos meios de comunicação e tecnológicos que reproduzem excessivamente essas imagens (cinema, fotografia etc.) e que essa mesma Cultura Visual não depende das imagens em si, mas sim "de plasmar nas imagens o visualizar das vivências". (MIRZOEFF, 2003, p. 20) O autor ainda acrescenta que esse movimento explorará dualidades, ambivalências, discursos e lugares de resistência do ponto de vista de quem consome.

Nesse sentido, há um entendimento de que o professor A trabalha com elementos da Cultura Visual, mas não tem clareza disso. Quando ele diz que as imagens dispostas nos livros didáticos no ensino de Geografia são recurso para prática pedagógica, ele está diante de artefatos da Cultura Visual, pois, a "reprodutibilidade técnica" (BENJAMIN, 1987), neste caso, impressa nos livros didáticos, é umas das características principais destes elementos. 
Quando este mesmo professor busca a internet e o site Google como opção de variedade de imagens, também está usando objetos inseridos na Cultura Visual que estão excessivamente reproduzidos, disseminados e consumidos através da rede. São essas imagens que ganham aderência pedagógica e possibilitam processos de ensino e aprendizagem.

O mesmo acontece com o professor B, quando relata utilizar a fotografia para facilitar o conteúdo estudado. O docente percebe que a imagem é um recurso e ainda infere os símbolos numéricos como também sendo imagens e representações. Um fato interessante é quando o professor atribui a Cultura Visual como sendo estudo de "arte". Esse indicativo de que a Cultura Visual se interessa pelo contemporâneo nos faz questionar quanto às obras de arte clássicas, que de certa forma, apresentam-se como objetos também visuais. Estariam elas também dentro desse contexto? Benjamim (1987) traz essa explanação quando compara uma obra de arte com a fotografia. Em suma, ele as diferencia indicando que a obra de arte possui uma "aura", aquilo que a coloca numa posição de singularidade, com características únicas que nenhum outro objeto tem, assim como valores atribuídos a ele. Porém, se esta mesma obra de arte for reproduzida tecnicamente e exposta pelos meios de comunicação de massa, aí sim, estarão inseridas no contexto da Cultura Visual.

\section{Educação e visualidades: práticas pedagógicas e possibilidades}

Mesmo quando não se reconhece a Cultura Visual como um campo de conhecimento, sabemos que a imagem é um artefato social mediado por educadores nas suas práticas. Contudo, as mudanças no meio educativo, que inclui texto imagético através dos recursos midiáticos e tecnológicos na sala de aula, levantaram alguns questionamentos sobre a real função pedagógica dessas imagens para o meio escolar. Estariam elas de fato educando? Ou estariam apenas servindo como mero objeto ilustrativo das aulas? Os docentes estariam utilizando-as de forma além do previsto, ou limitando esses recursos por falta de formação e orientação? Sobre isso e a frequência com que utilizam imagens na sala de aula, os professores narraram....

[...] Quase que sempre, porque uso muito imagens que tiro do Google. Olha, geografia é feita com imagens. É um meio comparativo, o antes 
ou depois, melhor, como era antes, como era depois... a mudança dos espaços pode ser vista com imagens. Outra coisa: como estudar hidrografia sem imagens? Ideal seria levar eles para ver ao vivo... mas não temos recursos, entende? Gosto da aula de campo por isso, porque tem o impacto do ver...eu não contei, eles que viram. É muito dificil, quase impossível levar por exemplo, para ver o mar e conhecer um litoral e suas características de vegetação, clima e tal...contamos com as imagens da internet e pá! Datashow!... fazer o quê? (PROFESSOR A, ENTREVISTA NARRATIVA, 2017)

Olha na minha área eu acho dificil trabalhar em sala de aula com imagem porque fisica é conta. Eu às vezes uso. (pausa longa) É difícil usar. É muita conta. É bem verdade que tem os desenhos para mostrar situações dos fenômenos, mas não vejo isso como fundamental. Fundamental é ele interpretar os problemas de Física. Aliás primeiro ele tem que saber fazer conta, depois conhecer as fórmulas e depois interpretar os problemas. Imagem aí... (pausa) Sei não... acho complicado porque somos de exatas...(pausa) olha não me lembro de trabalhar imagem na minha disciplina, quer dizer, já usei, mas muito muito pouco, mais no livro didático... só números (risos) Se número for imagem, então eu trabalho com imagem. (PROFESSOR B, ENTREVISTA NARRATIVA, 2017)

Na contramão da realidade contemporânea, inclusive dos estudantes, a Cultura Visual ainda aparece distante da realidade da prática de alguns professores. Em tempos de internet, redes sociais, mídias e novas tecnologias, não podemos mais fechar os olhos e negar o fato de que nossos estudantes estão envolvidos nesse referido meio. Chegam às escolas e às salas de aula "contaminados" nessa perspectiva dos meios de comunicação. Estamos todos e a todo momento conectados a esses elementos, mesmo que, em sua grande maioria, nem tenhamos conhecimento real disso. Ora, se enquanto profissionais da educação temos clareza disso, por que não trazer essas imagens para as práticas escolares? Como esses recursos visuais contribuiriam com o docente e o discente nesse sentido?

Como visto, o professor A contempla algumas dessas inquietações, quando diz que as imagens entram como recurso didático em suas aulas e reconhece que estas são de fundamental importância para a disciplina que ministra. Porém, há uma limitação no uso dessas imagens quando estas aparecem de forma meramente ilustrativas nos conteúdos de geografia. Aparentemente, essas vi- 
sualidades servem somente para ilustrar determinado conteúdo de forma superficial. Defendemos aqui que esses artefatos estão para além de ilustrações e exemplos. Visualidades que quando pensadas para atividades, projetos e planos de aula precisam ganhar valor e vigor nas possibilidades pedagógicas, considerando aquilo que chamamos de "pronunciamento visual". Segundo Silva (2006), é um entendimento entre a imagem produzida e a sua interpretação. Esse "pronunciamento visual" só é possível quando ocorre o que Hernandez (2006) vai denominar de "acontecimento visual": a experiência do sujeito com a imagem. Essas imagens podem ser fontes carregadas de valores morais, éticos, documentais, reflexões a respeito de temas diversos como gênero, sexualidade, sociedade, dentre tantos outros, todos passíveis de uma hermenêutica visual.

A fala do professor B revela o pouco uso das imagens em suas práticas escolares. Esta é, aliás, uma situação muito comum em algumas áreas do conhecimento, sobretudo em Ciências Exatas. Há certo desconforto dos docentes no trato com as visualidades, pois, trata-se de textos com possibilidades múltiplas de interpretações. Ademais, posturas como estas, expressas pelo depoimento do professor B, ignoram que artefatos como gráficos, animações, ilustrações e tabelas são recursos visuais que podem ser muito úteis ao desenvolvimento do aprendizado em qualquer área, inclusive das chamadas Ciências Exatas.

Como o texto imagético não se finda em suas leituras e intelecções, a produção de sentido se amplia consideravelmente, tornando esse artefato comumente silenciado pela escola e pelos profissionais que nela trabalham. A prática docente na utilização de imagens deve partir da orientação de inferências e interferências. Um fazer docente "[...] para realizar novas mediações, novas interseções. Mediar uma relação que já é mediada. Procurar dar sentido ao que já vem marcado por um sentido posto." (GOMES, 2008, p. 77)

Esse sentido, posto ao qual Gomes (2008) se refere, pode se configurar como aquilo que já está explícito, claro, diante dos olhos, o óbvio. Porém, a leitura das imagens invade uma outra configuração, naquilo que só as correlações, o conhecimento de mundo do leitor, o contexto da elaboração da imagem (histórico, geográfico, social, etc.) revelam. É nesse sentido que a prática docente entra como articuladora e mediadora, nesse processo de intelecção, desbravando essa "floresta" de símbolos que é o mundo das imagens, 
produzindo sentidos para captar as intenções dos discursos. Planos de aula, projetos e propostas podem ser pensados. A imagem ganha então uma aderência simbólica nas práticas escolares. Ela ganha uma serventia educativa.

Um educador mais atento ao contexto das vivências dos seus discentes vai perceber que as imagens fazem parte não só do dia a dia deles, mas do mundo. Isso se mostra nos programas de televisão e suas propagandas, nas redes sociais das quais fazemos parte (facebook, instagran, whatsapp, twitter), vestimentas, jogos, dentre outros artefatos. Para isso, é necessário que estejamos em sintonia com esses ambientes e com as visualidades, para sabermos aproveitar esses recursos e transformá-los em possibilidades de trabalho pedagógico que refletirão no que chamamos anteriormente de aprendizagem significativa.

Finalmente, podemos dizer que as entrevistas revelaram as "verdades" desses professores, através de suas narrativas que nos ajudam a compreender as trajetórias docentes e, por consequência, a sua formação.

Os professores entrevistados revelaram elementos que contemplaram análises de sua formação docente e do trabalho com imagens em sala de aula. Esse material pode ser correlacionado com outros estudos da temática, possibilitando reflexões, inferências e outras interpretações.

Nesse sentido, as duas narrativas indicam que os dois docentes fizeram a escolha da profissão docente como alternativa de vida e sobrevivência, e não, necessariamente, como opção oriunda do desejo de exercer a docência. Os entrevistados não optaram ser professor por vontade própria, o que nos faz questionar como isso pode comprometer a qualidade da sua prática pedagógica, implicando nas dimensões pessoais e profissionais, especialmente quando esses profissionais estão inseridos em contexto de não valorização profissional, salarial e de carreira.

Quanto à relação dos docentes com a Cultura Visual, percebemos por meio das narrativas, que as práticas escolares não têm acompanhado as transformações sociais, intensificadas com o advento das tecnologias digitais e, portanto, impregnada da Cultura Visual.

Quanto aos conceitos, os entrevistados afirmaram desconhecer o tema ou não ter segurança para falar a respeito. Demonstraram imprecisões e "achismos", o que podemos concluir ser natural, diante da subjugação da imagem nas práticas escolares. 
Contudo, no que diz respeito ao uso de imagens em práticas docentes, apenas um informante admitiu o uso para ilustrar conteúdos, enquanto o outro diz ser difícil o uso de imagens nas suas aulas de Física, cujas falas apontam para o fato de que nesse sentido, poderíamos dizer que há uma abertura maior dos professores da área de humanidades no trato com as imagens do que com os professores da área de exatas.

As narrativas demonstraram uma proximidade maior do professor de Geografia com o uso de imagens, visto que, mesmo utilizando-as a seu modo para a formação, concebe-as como necessárias e importantes, enquanto, que o outro professor não faz uso e não consegue percebê-las como recurso pedagógico para a sua área de ensino. No entanto, isso não se sustenta, principalmente quando consideramos que as imagens são representações de mundo. Não cabe aqui, a simples distinção das áreas. As possibilidades aparecem nos diversos campos de saberes e nas diversas áreas do conhecimento humano. O que nos indica que há um problema na formação docente, de modo diferente, nos dois casos.

\section{Considerações finais}

Levando em consideração que a formação de professores é um processo complexo que envolve dimensões sociais, intelectuais, políticas, culturais, econômicas e materiais, passamos a compreender que as experiências aqui refletidas são reflexos das condições de formação de boa parte do professorado brasileiro que lida com dificuldades de sobrevivência, poucas oportunidades de estudos e opções restritas na escolha da profissão. Além disso, é importante notar que a trajetória formativa dos professores aponta para fragilidades curriculares que têm tratado produções culturais cotidianas e corriqueiras (a exemplo das imagens) como algo distante e alheio à vida dos sujeitos.

Por fim, cabe nos lembrar que programas de formação de professores que considerem as imagens na sua riqueza de conhecimento e em diálogo com os contextos de ubiquidade nos quais vivemos, certamente, despertará nos profissionais da educação a ideia de que as visualidades são recursos fecundos para a produção de conhecimento, para ampliação das visões de mundo e para o desenvolvimento do pensamento relacional. Representam, no 


\title{
Teaching narratives and identities: visual culture and pedagogical practice
}

\begin{abstract}
This work takes as its object of investigation the oral narratives of teachers to, from them, understand the personal and professional trajectories of insertion in teaching. It aims to problematize the trajectory and teacher training from narratives and how this same path is positioned in dealing with images as a pedagogical practice inserted in the contemporary context of Visual Culture. It emphasizes, from then on, the perceptions and use of visual artifacts in classrooms as a possibility of knowledge production connected to the contemporary world, through visualities. To develop the work narrative interviews were conducted with two teachers of Basic Education, which shows the reasons why they opted for teaching and the ways of using images in the classroom. Research has shown us that although these issues present advances, they still retain visions restricted to the idea of visualities as illustration of contents or dispensable / inappropriate elements depending on the area of knowledge
\end{abstract}

Keywords: Training trajectories. Visual culture. Pedagogical practice.

\section{Enseñanza de narrativas e identidades: cultura visual y práctica pedagógica.}

\begin{abstract}
RESUMEN: Este trabajo toma como objeto de investigación las narraciones orales de los docentes para, a partir de ellos, comprender las trayectorias personales y profesionales de inserción en la enseñanza. Su objetivo es problematizar la trayectoria y la formación del profesorado a partir de las narrativas y cómo se posiciona este mismo camino al tratar con las imágenes como una práctica pedagógica insertada en el contexto contemporáneo de la Cultura Visual. Enfatiza, desde entonces, las percepciones y el uso de artefactos visuales en las aulas como una posibilidad de producción de conocimiento conectado al mundo contemporáneo, a través de las visualidades. Para desarrollar el trabajo se realizaron entrevistas narrativas con dos docentes de Educación Básica, que muestran las razones por las cuales optaron por la enseñanza y las formas de usar imágenes en el aula. La investigación nos ha demostrado que aunque estos problemas presentan avances, aún conservan visiones restringidas a la idea de visualidades como ilustración de contenidos o elementos prescindibles / inapropiados dependiendo del área de conocimiento.
\end{abstract}

Palabras clave: Trayectorias de formación. Cultura visual. Práctica pedagógica.

\section{REFERÊNCIAS}

BENJAMIN, Walter. Magia técnica, arte e política. Ensaios sobre literatura e história da cultura. Brasiliense. São Paulo. 1987. 
BARNARD, M. Approaches to understanding visual culture. New York: Palgrave, 2001.

FRASSON, M. V.; CAMPOS, L. M. L.; A opção pela licenciatura e pela profissão de professor: desvelando razões de alunos do curso de Ciências Biológicas. Revista da SBEnBIO, [s. l.], v. 3, p. 1562-1572, 2010.

GALEFFI, D.; MACEDO, R. S.; PIMENTEL, A. Um rigor outro. Salvador: Edufba, 2009.

GOMES, A. R. Linguagem imagética e educação. Guarapari: ExLibris, 2008.

HERNANDEZ, F. De la alfabetizacón visual al alfabetismo de la cultura visual. Barcelona: Universidad de Barcelona, 2006.

MACEDO, R. S. A etnopesqusia crítica e multirreferencial nas ciências humanas e na educação. Salvador: Edufba, 2000.

MITCHELL, W. J. T. Que és la cultura visual. Princenton: Irving Lavin Institute for Advanced Study, 1995.

MIRZOEFF, N. Una introducción a la cultura visual. Barcelona: Paidós, 2003.

NÓVOA, A. Os professores e sua formação. Lisboa: Publicações Dom Quixote: Instituto de Inovação Educacional, 2010.

PINEAU, G. As histórias de vida em formação: gênese de uma corrente de pesquisa ação-formação existencial. Educação e Pesquisa, São Paulo, v. 32, n. 2, p. 329-346, maio/ago. 2006.

REIS, A. O.; MUYLAERT, C. J.; SARUBBI, V.J.; GALLO, P. R.; NETO, M. L. R. Entrevistas narrativas: um importante recurso em pesquisa qualitativa. Revista da Escola de Enfermagem da USP,São Paulo, v. 48, p. 193-194, dez. 2014.

REIS, P. R. As narrativas na formação de professores e na investigação em educação. Nuances: Estudos sobre Educação, São Paulo, v. 15, n. 16, p. 1734, 2008.

SANTOS, L. M. M. O papel da família e dos pares na escolha profissional. Psicologia em Estudo, Maringá, v. 10, n. 1, p. 57-66, 2005.

SILVA, S. L. P. da. Identidade e novas mídias: a cultura visual no processo de investigação das ciências sociais. Interseções, Rio de Janeiro, v. 15, p. 83-94, 2006.

SOARES, D.H.P. A escolha profissional: do jovem ao adulto. São Paulo: Summus Editorial, 2002.

SOUZA, E. C. de. Territórios das escritas do eu: pensar a profissão - narrar a vida. Educação, Porto Alegre, v. 34, n. 2, p. 213-220, maio/ago. 2011.

SOUZA, E. C. de. O conhecimento de si: estágio e narrativas de formação de professores. Rio de Janeiro: DPEA; Salvador: UNEB, 2006a. 
SOUZA, E. C. de. A arte de contar e trocar experiências: reflexões teórico-metodológicas sobre as histórias de vida em formação. Educação em questão, Natal, v. 25, n. 11, p. 22-39, jan./abr. 2006b.

Submetido em: 12/02/2019

Aceito em: 21/12/2019 